\title{
Cell-free DNA Testing: Where are We now?
}

\author{
${ }^{1}$ Cihat Sen, ${ }^{2}$ Olus Api, ${ }^{3}$ Murat Yayla, ${ }^{4}$ Gokhan Goynumer
}

\section{ABSTRACT}

Prenatal screening for fetal aneuploidies has been focused on mainly Down syndrome in the last 40 years. The method of screening has changed from maternal age in the 1970s, with a detection rate of 30 and $5 \%$ false positive rate (FPR), to a combination of maternal age and second-trimester serum biochemical markers (triple test and quadruple test) in the 1980s and 1990 s, with 60 to $75 \%$ detection rate and $5 \%$ false positive rate (FPR). Following this, the era of first trimester screening for Down syndrome has started with the clinical implementation of fetal nuchal translucency screening. The combination of maternal age, NT thickness and serum free beta-human chorionic gonadotropin ( $\beta-\mathrm{hCG}$ ) and pregnancy-associated plasma protein A (PAPP-A) in the first trimester has yielded a $90 \%$ detection rate with a $5 \%$ FPR. Starting from the year 2008 , studies have shown that the performance of screening may be improved by analysis of cell-free deoxyribonucleic acid (DNA) (cfDNA) in maternal blood. Several studies in the last few years have reported the clinical validation of cell free fetal DNA test in the maternal serum in screening for trisomies 21,18 , and 13 and sex chromosome aneuploidies.

Its widespread use is limited by the relatively high cost of the test and the lack of consensus about the optimal way for its clinical implementation. Until the optimal way of incorporating cfDNA into the clinical practice gets identified, it would be wise not to substitute cfDNA testing in place of first-trimester screening for fetal defects and other major complications of pregnancy. Furthermore, it would be preferable for clinicians managing individual patients not to counsel them for their result as positive or negative, rather the clinicians should use the risk estimate from the first-line method of screening as the prior risk and modify this by the appropriate positive or negative likelihood ratio from the cfDNA test.

Keywords: Chromosomal abnormalities, Fetal DNA, Screening.

How to cite this article: Sen C, Api O, Yayla M, Goynumer G. Cell-free DNA Testing: Where are We now? Donald School J Ultrasound Obstet Gynecol 2016;10(2):172-177.

Source of support: Nil

Conflict of interest: None

\footnotetext{
${ }^{1,3}$ Professor, ${ }^{2,4}$ Associate Professor

${ }^{1}$ Department of Perinatal Medicine, Cerrahpasa Medical School Istanbul University, Istanbul, Turkey

${ }^{2}$ Department of Perinatal Medicine, Yeditepe University Medical School, Istanbul, Turkey

${ }^{3}$ Clinics of Gynecology and Obstetrics, Acibadem International Hospital, Istanbul, Turkey

${ }^{4}$ Clinics of Gynecology and Obstetrics, Medeniyet University Medical School and Goztepe Teaching and Research Hospital Istanbul, Turkey
}

Corresponding Author: Cihat Sen, Perinatal Medicine Foundation, Cumhuriyet cad 30/5, Elmadag, Istanbul, Turkey e-mail: csen@cihatsen.com

\section{INTRODUCTION}

Fetal chromosomal abnormalities including Down syndrome and other trisomies are common. In antenatal care, one of the most important objectives of the obstetricians and perinatologists is to detect these anomalies with $100 \%$ detection rate. Prenatal diagnosis of fetal chromosomal abnormalities requires invasive procedures, such as chorion villus sampling (CVS), amniocentesis, or fetal blood sampling, all of which are associated with the risk of fetal loss. ${ }^{1}$ Furthermore, they carry the disadvantage of being expensive and requiring special expertise. As a consequence, many screening tests have been developed in order to identify the high-risk group which is in need for the "risky and expensive" invasive testing.

Prenatal screening for fetal aneuploidies has been focused on mainly Down syndrome in the last 40 years. The method of screening has changed from maternal age in the 1970s, with a detection rate of 30 and 5\% false-positive rate (FPR), to a combination of maternal age and second-trimester serum biochemical markers (triple test and quadruple test) in the 1980s and 1990s, with 60 to $75 \%$ detection rate and 5\% FPR. Following this, the era of first-trimester screening for Down syndrome has started with the clinical implementation of fetal nuchal translucency (NT) screening. The combination of maternal age, NT thickness, and serum free beta-human chorionic gonadotropin ( $\beta$-hCG) and pregnancy-associated plasma protein A (PAPP-A) in the first trimester has yielded a 90\% detection rate with a 5\% FPR. ${ }^{2}$ Starting from the year 2008, studies have shown that the performance of screening may be improved by analysis of cell-free deoxyribonucleic acid (cfDNA) in maternal blood. Several studies in the last few years have reported the clinical validation of fetal cfDNA test in the maternal serum in screening for trisomies 21,18 , and 13 and sex chromosme aneuploidies. A meta-analysis of clinical validation studies reported detection rates for trisomies 21,18 , and 13 of 99,96 , and $91 \%$, respectively, at an overall FPR of $0.35 \% .^{3}$ Sensitivities for trisomy 13 and sex chromosome abnormalities are some what lower, averaging 80 to $90 \%$, but the specificity remains greater than $99 \%$ for each condition.

In this article we aim to review the recent scientific evidence on the clinical use of cfDNA in maternal blood for fetal aneuploidies and provide suggestions for the introduction of this method in perinatology practice. 


\section{BRIEF HISTORY OF cfDNA TESTING}

In the year 1893, a German pathologist Georg Schmorl was the first to describe fetal trophoblasts in maternal lungs of women who died from eclampsia. ${ }^{4} \mathrm{He}$ also recognized that fetomaternal trafficking occurred in normal gestations but was increased in pregnancies affected by eclampsia. Following this, there has been an approximately 100 years of long hiatus till the clinical application of cfDNA in aneuoploidy screening. The concept of fetal aneuploidy screening by the analysis of cfDNA in maternal plasma became possible after the discovery in 1997 that a high proportion of cfDNA fragments in maternal plasma are of fetal origin. ${ }^{5}$ The first clinical application of the use of cfDNA has been performed in the noninvasive diagnosis of the fetal Rhesus D status. ${ }^{6}$ Following this important innovation, intensive research in recent years has led to the development of many commercially available methods of analyzing cfDNA in maternal blood for fetal aneuploidies and other types of genetic abnormalities, such as single gene disorders and sex chromosome abnormalities. It has recently been shown that contingent screening for trisomy 21 by the first-trimester combined test incorporating the option of cfDNA testing is a reasonable method for prenatal detection, which has a lower invasive testing rate than in screening by the combined test alone. $^{7}$

\section{CLINICAL USE OF CfDNA TESTING IN MATERNAL BLOOD}

As previously described, cfDNA testing works by analyzing the DNA fragments present in the maternal plasma during pregnancy. Most of this cfDNA is the maternal cfDNA, but around 3 to $13 \%$ of cfDNA in the circulation of a pregnant woman comes from the fetus. ${ }^{8}$ Cell-free DNA is known to be first detectable from about 4 to 5 weeks' gestation; however, the level of cfDNA is not high enough for analysis at this period of gestation. The cfDNA reaches a level suitable for analysis at different gestations according to what is being tested for. However, most commercially available cfDNA tests are able to yield results for trisomy 21 starting from 9 weeks of gestation. ${ }^{9}$ It is also important to note that the cfDNA is cleared from the maternal circulation within the first hour after birth; therefore, the cfDNA does not represent the genetic properties of the previously born fetuses.

Three methods for the analysis of cfDNA in maternal blood have so far been reported in clinical studies: massively parallel shotgun sequencing (MPSS), 10,11 chromosome-selective sequence analysis (CSS), ${ }^{12,13}$ and single-nucleotide polymorphism (SNP)-based analysis. ${ }^{14,15}$ Sequencing DNA fragments can reveal the extra representation of DNA from a trisomy. Additionally, it seems theoretically possible to analyze the whole fetal genome, but this represents a major challenge on economical and ethical grounds. ${ }^{16}$ Therefore, the first generation of commercial tests has mainly concentrated on the detection of trisomies 21, 18, and 13, and sex chromosome aneuploidies. Following this, some selected type of fetal genomic microdeletion syndromes have recently been analyzed by cfDNA testing; however, sensitivity and specificity have not been systematically evaluated. ${ }^{17}$ Commercial companies have begun to offer expanded panels including screening for common microdeletion syndromes such as 22q11.2 deletion. However, the performance data for these microdeletion syndromes still remain to be derived from a small number of samples due to the rarity of these syndromes. ${ }^{18}$ One of the major goals of cfDNA testing is the prenatal detection of single gene disorders. There are many studies on the detection of single gene disorders, such as achondroplasia, thanatophoric dysplasia, Apert syndrome, beta-thalassemia, etc. ${ }^{19-22}$ Furthermore, a recent promising development has been the utilization of cfDNA in mothers carrying at-risk fetuses for congenital adrenal hyperplasia (CAH) as early as 6 gestational weeks by targeted massively parallel sequencing of the genomic region including the CYP21A2 gene. ${ }^{23}$ This innovative approach may aid for the diagnosis of $\mathrm{CAH}$ before genital development begins, therefore restricting the purposeful administration of dexamethasone to mothers known to be carrying affected female fetuses. ${ }^{24}$

When it comes to discuss the clinical utility of sex chromosome analysis by the use of cfDNA in maternal blood, accuracy of sex determination generally exceeds $98 \%{ }^{8,10,25}$ Early prenatal diagnosis of fetal sex would be quite useful to manage the pregnancy in cases with a risk of some heritable disorders. The demonstration of cfDNA in the mother's blood has made it possible to identify $Y$ chromosome sequences in maternal blood during the first trimester. Cell-free DNA testing can significantly reduce the number of invasive procedures for women with fetuses at risk of sex-linked diseases. Although the fetal sex can be diagnosed by ultrasound with the same sensitivity and specificity, the diagnosis would be much more later than the results of cfDNA testing. However, there are also some ethical concerns about reporting the sex chromosome analysis results to the parents-to-be. First of all, sex chromosomal abnormalities such as Turner syndrome $(X 0)$ and triple $X$ syndrome $(X X X)$ can be reliably diagnosed by cfDNA testing if the maternal "background" can be excluded from testing. The benefits to the harms of the detection of these types of sex chromosome abnormalities which are without mental retardation and compatible with life should be balanced with regard to its psychological, ethical, legal, 
social, and economic implications. On the contrary, there seems to be a possible risk of the use of cfDNA testing for selective abortion based on sex selection of the fetus; therefore, it is feared that informed consent may become more difficult, that both testing and selective abortion may become "normalized." 26 Therefore, for the present time, it seems to be wise to advise to withdraw the offer to screen if the patient claims to want information only on the sex chromosomes.

As previously described, three methods for the analysis of cfDNA in maternal blood have so far been reported in clinical studies: MPSS, ${ }^{10,11}$ CSS, ${ }^{12,13}$ and SNP-based analysis. ${ }^{14,15}$ In MPSS, molecules from all chromosomes are examined with the potential to identify all aneuploidies. This method provides high-performance screening for trisomies 21, 18, and 13 and sex chromosome aneuploidies with a low $(<2 \%)$ failure rate to provide results. ${ }^{27}$ Additionally, the MPSS-based cfDNA tests have recently launched extended testing to include screening for some microdeletion/microduplication syndromes. In CSS, selective assays are directed against specific regions on chromosomes $21,18,13, \mathrm{X}$, and $\mathrm{Y}$ before sequence analysis. Chromosome-selective sequence analysis also evaluates polymorphisms on other chromosomes to estimate the fetal fraction. ${ }^{27}$ The advantage of this approach is its reduced cost because the number of regions that need to be sequenced is substantially lower, but it carries the disadvantage of having a higher failure rate $(2-4 \%)$ than MPSS-based cfDNA testing.

Single-nucleotide polymorphism-based cfDNA testing uses the principle that the fetus has different SNPs than the mother. ${ }^{27-29}$ Single-nucleotide polymorphisms are simple variations in DNA that help distinguish among individuals. The method detects if there are differences in the maternal and fetal SNPs belonging to a given chromosome and uses complex mathematical calculations to estimate if the distribution of the fetal SNPs with respect to the maternal SNPs is compatible with monosomy, disomy, or trisomy. The reported performance for trisomies 21, 18, and 13 of SNP-based testing is similar to that of MPSS and CSS, and this method of cfDNA testing can identify further abnormalities, such as triploidy which cannot be detected via MPSS- and CSS-based cfDNA testing and may yield reliable results in case of "vanishing" twin pair. ${ }^{29}$

Another issue with cfDNA screening is the fetal fraction, which should exceed $4 \%$ to generate accurate results according to most laboratories, using any kind of technology such as MPSS, CSS, or SNP-based testing. "Test failure" occurs in 1 to $8 \%$ of samples and may also be reported as "no call," "indeterminate," or "uninterpretable." ${ }^{\prime 9}$ It has been shown that up to $23 \%$ of women who receive these questionable results carried aneuploid fetuses. ${ }^{9}$ Repeating the screen yields results in only 50 to $60 \%$ of cases. ${ }^{30}$ However, in a recent cohort study of 10,698 singleton pregnancies undergoing screening for fetal trisomies 21,18 , and 13 by cfDNA testing in the first trimester, it was reported that there was a failed result from cfDNA testing after first sampling in $2.9 \%$ of the unaffected group, $1.9 \%$ of trisomy $21,8.0 \%$ of trisomy 18 , and $6.3 \%$ of trisomy $13 .{ }^{31}$ Therefore, the authors have concluded that in cases of failed cfDNA test the rate of trisomies 18 and 13, but not trisomy 21, were higher than in those with a successful test. Consequently, it was advised that the decision in favor of invasive testing should depend on the risk of prior screening and the results of detailed ultrasound examination in the management of such "no call" cases. In this trial, the authors also reported that the risk of test failure increased with increasing maternal age and body mass index and increased with decreasing PAPP-A and free $\beta$-hCG MoM. Furthermore, it was shown that the risk of "no call" result was also higher in South Asian than Caucasian racial origin and in pregnancies achieved by assisted reproduction than spontaneous conception. ${ }^{31}$

As a very recent finding, it has been reported in a small group of study population that the administration of low-molecular-weight heparin (LMWH) significantly influences the quality of cfDNA testing and thus ultimately the accuracy of the test result. ${ }^{32}$ However, the molecular cause of the effect of LMWH has not been fully explained. Therefore, until greater number of cases are gathered, it has been advised to report the use of LMWH prior to cfDNA testing to the laboratory and to ensure that blood sample is drawn shortly before the next administration of LMWH when its level is at the lowest in the patient's plasma. ${ }^{32}$

The other important issue with cfDNA screening is the false-positive and false-negative rates of the commercially available tests. False-positive test results are known to arise from placental mosaicism, maternal malignancy, maternal chromosomal duplication, multiple gestation, including a vanishing twin, use of a donor egg, consanguinity, and bone marrow transplant. ${ }^{33-35}$ It is important to underline that maternal cancers most frequently occurred with the rare cfDNA test finding of more than one aneuploidy detected. ${ }^{34}$ False-negative results are much rarer than false-positive test results, but it should be noted that they can arise for a triploid fetus especially if methods other than SNP-based tests such as MPSS- or CSS-based tests have been used. Therefore, it is very important to emphasize that cfDNA testing for aneuploidy is still considered screening and not diagnostic. In case of a positive cfDNA testing for any type of aneuploidy, its confirmation should be war-ranted by prenatal invasive testing, such as CVS or amniocentesis. 
Studies conducted since 2012 indicate that the sensitivity and specificity of fetal cfDNA screening are similar in the high risk and general obstetric populations. ${ }^{9}$ However, positive predictive value is lower in the general group because the prevalence of aneuploidy is much lower. The American Congress of Obstetricians and Gynecologists and the Society for Maternal-Fetal Medicine have encouraged laboratories to report results with positive predictive values (probability that a positive result is a true positive one) as well as residual risk values (probability that a negative result is a truly negative one) for each result that indicates increased risk for aneuploidy. ${ }^{36}$ For example, based on the sensitivity and specificity of any method of cfDNA test, when a population with an overall prevalence of $1 / 1,000$ for trisomy 21 is screened, the positive predictive value of an abnormal result is 33\%, $1 \mathrm{in} 3$ women will have an affected fetus. If the prevalence is $1 / 75$, the positive predictive value is $87 \%$. ${ }^{3,9}$

Although cfDNA testing is highly effective in screening for trisomies and the test carries the advantage of being noninvasive for the fetus, therefore not increasing the risk of fetal loss, the widespread use of cfDNA testing is at present limited by the relatively high cost of the test and the lack of consensus about the optimal way for its clinical implementation.

Consequently, many models for clinical implementation of cfDNA testing in screening for trisomies have been suggested. In 2013 and 2014, Nicolaides et al ${ }^{37,38}$ proposed the use of the first-trimester combined test as a triage examination for cfDNA assessment. This clinical strategy would help to retain the advantages of first-trimester testing by ultrasound and biochemistry, including accurate pregnancy dating, early detection of many major fetal defects, and prediction of common pregnancy complications, such as preterm birth and preeclampsia. ${ }^{38}$ According to the first proposed clinical model, in contingent screening, detection of $98 \%$ of fetuses with trisomy 21 at an overall invasive testing rate of $<0.5 \%$ was reported to be achieved by offering cfDNA testing to about 36,21 , and $11 \%$ of cases identified by first-line screening using the combined test alone, using the combined test with the addition of serum placental growth factor (PlGF) and serum alpha-fetoprotein (AFP), and using the combined test with the addition of PlGF, AFP, and ductus venosus pulsatility index for veins (DV-PIV) respectively. ${ }^{37}$ Such a policy has generally been based on first-trimester combined testing for all patients and assessment of cfDNA as a secondary test in a smaller proportion of pregnancies. For example, if the cfDNA test is reserved for the $25 \%$ of pregnancies with a risk from the combined test of trisomy $21 \geq 1: 2,500$, the overall performance would be almost as good as if cfDNA testing was carried out in all pregnancies. ${ }^{37}$
Another model of screening for major trisomies by maternal age, fetal NT thickness, and DV-PIV followed by cfDNA testing in pregnancies with an intermediate risk has been proposed by the same group in $2014 .{ }^{39}$ The combined test followed by invasive testing in the highrisk group $(\geq 1: 10)$ and cfDNA testing in the intermediaterisk group $(1: 11-1: 3,000)$ have been found to potentially detect about 96,95 , and $91 \%$ of cases for trisomy 21, 18, and 13 , respectively, with a total FPR of $0.8 \% .{ }^{39}$ The overall cost of such a policy was assumed to be $€ 250$ per patient, whereas the alternative policy of universal screening by cfDNA testing could potentially detect about 99, 97, and $92 \%$ of cases of trisomies 21,18 , and 13 , but at an overall cost of more than $€ 500$ per patient. $^{39}$

Other clinical models proposed contingent policies that use the first-trimester combined test for first-line screening to select the subgroup for cfDNA testing; the data from the latter has been suggested to be used to update the risk from the former. ${ }^{40,41}$ According to the first study, when a fetus is affected, if cfDNA testing gives a high-risk result, the likelihood was calculated to be $1,240,650$, and 460 for trisomies 21,18 , and 13 respectively. ${ }^{40}$ Consequently, the chance for a fetus from a pregnancy to be truly affected would depend on the prior risk for that pregnancy. As an example, if prior screening by the combined test had shown that the risk for trisomy 21 was 1 in 12,400 and cfDNA testing gave a high-risk result, the risk in this case is about 1 in 10. On the contrary, if the risk from the combined test was 1 in 2,480, the risk for an affected fetus is 1 in 2 . $^{27,40}$ Similarly, when cfDNA testing gives a low-risk result, the negative likelihood was calculated to be 1,000, 31, and 13 for trisomies 21,18 , and 13 respectively. ${ }^{40}$ Consequently, the chance for that pregnancy to be truly affected would depend on the prior risk for that pregnancy. For example, if prior screening by the combined test had shown that the risk for trisomy 21 was 1 in 500 and cfDNA testing gives a low-risk result, the risk for an affected fetus is 1 in 500,000; on the contrary, if the risk for trisomy 13 from the combined test was 1 in 2 and cfDNA testing gives a low-risk result, the risk for an affected fetus is 1 in $26 .^{27,40}$

According to the other study, the fetal fraction was found to be affecting these above-mentioned positive and negative likelihood ratios. ${ }^{41}$ For example, the detection rate of trisomy 21 increased from $62 \%$ at a fetal fraction of 4 to $100 \%$ at a fetal fraction of $\geq 9 \%$; the positive likelihood ratio increased from 620 to 1,000 and the negative likelihood ratio increased from 3 to $>10,000$. In this model, even when the fetal fraction is $<4 \%$, which is usually considered as a test failure, it has been shown that the cfDNA results could be used to improve the performance of screening by the combined test. ${ }^{41}$

Finally, a recent study (2016) has examined the routine clinical implementation of contingent screening in 11,692 
singleton pregnancies in two National Health Service hospitals in the UK. ${ }^{7}$ Women with a risk $\geq 1$ in 100 (highrisk group) were offered options of invasive testing, cfDNA testing, or no further testing, and those with a risk between 1 in 101 and 1 in 2,500 (intermediate-risk group) were offered cfDNA testing or no further testing. ${ }^{7}$ According to the results of this study, about $98 \%$ of women accepted the offer of screening for fetal trisomies by the combined test and this was carried out successfully in all cases. In the high-risk group, 38\% of women opted for invasive testing, $60 \%$ for cfDNA testing, and $2 \%$ for no further tests. In the intermediate-risk group, $91.5 \%$ opted for cfDNA testing and $8.5 \%$ for no further tests. Regarding termination of pregnancy following prenatal detection of trisomy 21 , this was chosen in $74 \%$ of the study population. With this policy, about $30 \%$ of population had additionally cfDNA test with a combined test in clinical practice. The combined test had a potential detection rate of $87 \%$ for trisomy 21 and $93 \%$ for trisomies 18 or 13 at an FPR of $3.4 \%$; the respective values for the cfDNA test were 98,82 , and $0.25 \%$. Therefore, it is estimated that the introduction of cfDNA testing was associated with a $43 \%$ reduction in the rate of invasive testing. In that study, the authors highlighted that, in real life, prenatal detection of trisomies and pregnancy outcome depends not only on performance of screening tests but also on parental choice. Clinical implementation of cfDNA testing, contingent on the results of the combined test, may have only a modest impact in reducing the rate of invasive testing and a small effect on the rate of live births with trisomy $21 .{ }^{7}$

\section{CONCLUSION}

The use of cfDNA in maternal blood for the detection of fetal rhesus D antigen status, fetal sex, and common chromosomal aneuploidies is now well established, although testing for aneuploidy is still considered screening and not diagnostic. However, its widespread use is limited by the relatively high cost of the test and the lack of consensus about the optimal way for its clinical implementation. Until the optimal way of incorporating cfDNA into clinical practice gets identified, it would be wise not to substitute cfDNA testing in place of first-trimester screening for fetal defects and other major complications of pregnancy. Furthermore, it would be preferable for clinicians managing individual patients not to counsel them for their result as positive or negative, rather the clinicians should use the risk estimate from the first-line method of screening as the prior risk and modify this by the appropriate positive or negative likelihood ratio from the cfDNA test. New advances in technology and bioinformatics may extend to the noninvasive detection of fetal subchromosomal aneuploidy, single gene disorders, and the entire fetal genome.

\section{REFERENCES}

1. Tabor A, Alfirevic Z. Update on procedure related risks for prenatal diagnosis techniques. Fetal Diagn Ther 2010;27(1):1-7.

2. Spencer K, Souter V, Tul N, Snijders R, Nicolaides KH. A screening program for trisomy 21 at 10-14 weeks using fetal nuchal translucency, maternal serum free beta-human chorionic gonadotropin and pregnancy-associated plasma protein-A. Ultrasound Obstet Gynecol 1999 Apr;13(4):231-237.

3. Gil MM, Quezada MS, Revello R, Akolekar R, Nicolaides KH. Analysis of cell-free DNA in maternal blood in screening for fetal aneuploidies: updated meta-analysis. Ultrasound Obstet Gynecol 2015 Mar;45(3):249-266.

4. Lapaire O, Holzgreve W, Oosterwijk JC, Brinkhaus R, Bianchi DW. Georg Schmorl on trophoblasts in the maternal circulation. Placenta 2007 Jan;28(1):1-5.

5. Lo YM, Corbetta N, Chamberlain PF, Rai V, Sargent IL, Redman CW, Wainscoat JS. Presence of fetal DNA in maternal plasma and serum. Lancet 1997 Aug 16;350(9076):485-487.

6. Lo YM, Hjelm NM, Fidler C, Sargent IL, Murphy MF, Chamberlain PF, Poon PM, Redman CW, Wainscoat JS. Prenatal diagnosis of fetal RhD status by molecular analysis of maternal plasma. N Engl J Med 1998 Dec 10;339(24):1734-1738.

7. Gil MM, Revello R, Poon LC, Akolekar R, Nicolaides KH. Clinical implementation of routine screening for fetal trisomies in the UK NHS: cell-free DNA test contingent on results from first-trimester combined test. Ultrasound Obstet Gynecol 2016 Jan;47(1):45-52.

8. Norton ME, Brar H, Weiss J, Karimi A, Laurent LC, Caughey AB, Rodriguez MH, Williams J 3rd, Mitchell ME, Adair CD, et al. Non-Invasive Chromosomal Evaluation (NICE) study: results of a multicenter prospective cohort study for detection of fetal trisomy 21 and trisomy 18. Am J Obstet Gynecol 2012 Aug;207(2):137.e1-137.e8.

9. Committee Opinion No. 640. Cell-free DNA screening for fetal aneuploidy. Obstet Gynecol 2015 Sep;126(3):e31-e37.

10. Palomaki GE, Kloza EM, Lambert-Messerlian GM, Haddow JE, Neveux LM, Ehrich M, van den Boom D, Bombard AT, Deciu C, Grody WW, et al. DNA sequencing of maternal plasma to detect Down syndrome: an international clinical validation study. Genet Med 2011 Nov;13(11):913-920.

11. Bianchi DW, Platt LD, Goldberg JD, Abuhamad AZ, Sehnert AJ, Rava RP. Genome-wide fetal aneuploidy detection by maternal plasma DNA sequencing. Obstet Gynecol 2012 May;119(5):890-901.

12. Sparks AB, Struble CA, Wang ET, Song K, Oliphant A. Noninvasive prenatal detection and selective analysis of cell-free DNA obtained from maternal blood: evaluation for trisomy 21 and trisomy 18. Am J Obstet Gynecol 2012 Apr;206(4):319.e1-319.e9.

13. Ashoor G, Syngelaki A, Wagner M, Birdir C, Nicolaides KH. Chromosome-selective sequencing of maternal plasma cell-free DNA for first-trimester detection of trisomy 21 and trisomy 18. Am J Obstet Gynecol 2012 Apr;206(4):322. e1-322.e5.

14. Zimmermann B, Hill M, Gemelos G, Demko Z, Banjevic M, Baner J, Ryan A, Sigurjonsson S, Chopra N, Dodd M, et al. Noninvasive prenatal aneuploidy testing of chromosomes 13, $18,21, X$, and $Y$ using targeted sequencing of polymorphic loci. Prenat Diag 2012 Dec;32(13):1233-1241.

15. Nicolaides KH, Syngelaki A, Gil M, Atanasova V, Markova D. Validation study of maternal blood cell-free DNA testing by 
targeted sequencing of single-nucleotide polymorphisms at chromosomes 13, 18, 21, X, and Y. Prenat Diagn 2013 Jun;33(6):575-579.

16. Wong FC, Lo YM. Prenatal diagnosis innovation: genome sequencing of maternal plasma. Annu Rev Med 2016 Jan 14;67:419-432.

17. Yatsenko SA, Peters DG, Saller DN, Chu T, Clemens M, Rajkovic A. Maternal cell-free DNA-based screening for fetal microdeletion and the importance of careful diagnostic follow-up. Genet Med 2015 Oct;17(10):836-838.

18. Yaron Y, Jani J, Schmid M, Oepkes D. Current status of testing for microdeletion syndromes and rare autosomal trisomies using cell-free DNA technology. Obstet Gynecol 2015 Nov;126(5):1095-1099.

19. Chitty LS, Mason S, Barrett AN, McKay F, Lench N, Daley R, Jenkins LA. Non-invasive prenatal diagnosis of achondroplasia and thanatophoric dysplasia: next generation sequencing allows for a safer, more accurate and comprehensive approach. Prenat Diagn 2015 Jul;35(7):656-662.

20. van den Oever JM, Bijlsma EK, Feenstra I, Muntjewerff N, Mathijssen IB, Bakker E, van Belzen MJ, Boon EM. Noninvasive prenatal diagnosis of Huntington disease; detection of the paternally inherited expanded CAG repeat in maternal plasma. Prenat Diagn 2015 Oct;35(10):945-949.

21. Xu Y, Li X, Ge HJ, Xiao B, Zhang YY, Ying XM, Pan XY, Wang L, Xie WW, Ni L, et al. Haplotype-based approach for noninvasive prenatal tests of Duchenne muscular dystrophy using cell-free fetal DNA in maternal plasma. Genet Med 2015 Nov;17(11):889-896.

22. Xiong L, Barrett AN, Hua R, Tan TZ, Ho SS, Chan JK, Zhong M, Choolani M. Non-invasive prenatal diagnostic testing for betathalassaemia using cell-free fetal DNA and next generation sequencing. Prenat Diagn 2015 Mar;35(3):258-265.

23. New MI, Tong YK, Yuen T, Jiang P, Pina C, Chan KC, Khattab A, Liao GJ, Yau M, Kim SM, et al. Noninvasive prenatal diagnosis of congenital adrenal hyperplasia using cell-free fetal DNA in maternal plasma. J Clin Endocrinol Metab 2014 Jun;99(6):E1022-E1030.

24. Khattab A, Yuen T, Sun L, Yau M, Barhan A, Zaidi M, Lo YM, New MI. Noninvasive prenatal diagnosis of congenital adrenal hyperplasia. Endocr Dev 2016;30:37-41.

25. Bianchi DW, Parsa S, Bhatt S, Halks-Miller M, Kurtzman K, Sehnert AJ, Swanson A. Fetal sex chromosome testing by maternal plasma DNA sequencing: clinical laboratory experience and biology. Obstet Gynecol 2015 Feb;125(2): 375-382.

26. Gekas J, Langlois S, Ravitsky V, Audibert F, van den Berg DG, Haidar H, Rousseau F. Non-invasive prenatal testing for fetal chromosome abnormalities: review of clinical and ethical issues. Appl Clin Genet 2016 Feb 4;9:15-26.

27. Gratacós E, Nicolaides K. Clinical perspective of cell-free DNA testing for fetal aneuploidies. Fetal Diagn Ther 2014;35(3): 151-155.

28. Nicolaides KH, Syngelaki A, Gil M, Atanasova V, Markova D. Validation study of maternal blood cell-free DNA testing by targeted sequencing of single-nucleotide polymorphisms at chromosomes 13, 18, 21, X, and Y. Prenat Diagn 2013 Jun;33(6):575-579.

29. Nicolaides KH, Syngelaki A, Gil MM, Quezada MS, Zinevich Y. Prenatal detection of triploidy from cell-free DNA testing in maternal blood. Fetal Diagn Ther 2014;35(3):212-217.

30. Willems PJ, Dierickx H, Vandenakker E, Bekedam D, Segers N, Deboulle K, Vereecken A. The first 3,000 Non-Invasive Prenatal Tests (NIPT) with the Harmony test in Belgium and the Netherlands. Facts Views Vis Obgyn 2014;6(1):7-12.

31. Revello R, Sarno L, Ispas A, Akolekar R, Nicolaides KH. Screening for trisomies by cell-free DNA testing of maternal blood: consequences of failed result. Ultrasound Obstet Gynecol 2016 Jan 7. doi: 10.1002/uog.15851. [Epub ahead of print].

32. Grömminger S, Erkan S, Schöck U, Stangier K, Bonnet J, Schloo R, Schubert A, Prott EC, Knoll U, Stumm M, et al. The influence of low molecular weight heparin medication on plasma DNA in pregnant women. Prenat Diagn 2015 Nov;35(11):1155-1157.

33. Grati FR, Malvestiti F, Ferreira JC, Bajaj K, Gaetani E, Agrati C, Grimi B, Dulcetti F, Ruggeri AM, De Toffol S, et al. Fetoplacental mosaicism: potential implications for falsepositive and false-negative noninvasive prenatal screening results. Genet Med 2014 Aug;16(8):620-624.

34. Hall AL, DrendelHM, VerbruggeJL, Reese AM, Schumacher KL, Griffith CB, Weaver DD, Abernathy MP, Litton CG, Vance GH. Positive cell-free fetal DNA testing for trisomy 13 reveals confined placental mosaicism. Genet Med 2013 Sep;15(9): 729-732.

35. Bianchi DW, Chudova D, Sehnert AJ, Bhatt S, Murray K, Prosen TL, Garber JE, Wilkins-Haug L, Vora NL, Warsof S, et al. Noninvasive prenatal testing and incidental detection of occult maternal malignancies. JAMA 2015 Jul 14;314(2):162-169.

36. The American Congress of Obstetricians and Gynecologists. NIPT Cell Free DNA Screening Predictive Value Calculator. National Society of Genetic Counselors (NSGC) and Perinatal Quality Foundation (PQF). Endorsed Dec 2015. Available from: http:/ / www.acog.org/Resources-and-Publications / Endorsed-Documents.

37. Nicolaides KH, Wright D, Poon LC, Syngelaki A, Gil MM. First-trimester contingent screening for trisomy 21 by biomarkers and maternal blood cell-free DNA testing. Ultrasound Obstet Gynecol 2013 Jul;42(1):41-50.

38. Nicolaides KH, Syngelaki A, Poon LC, Gil MM, Wright D. First-trimester contingent screening for trisomies 21, 18 and 13 by biomarkers and maternal blood cell-free DNA testing. Fetal Diagn Ther 2014;35(3):185-192.

39. Kagan KO, Wright D, Nicolaides KH. First-trimester contingent screening for trisomies 21,18 and 13 by fetal nuchal translucency and ductus venosus flow and maternal blood cell-free DNA testing. Ultrasound Obstet Gynecol 2015 Jan;45(1):42-47.

40. Gil MM, Akolekar R, Quezada MS, Bregant B, Nicolaides KH. Analysis of cell-free DNA in maternal blood in screening for aneuploidies: meta-analysis. Fetal Diagn Ther 2014;35(3):156-173.

41. Wright D, Wright A, Nicolaides KH. A unified approach to risk assessment for fetal aneuploidies. Ultrasound Obstet Gynecol 2015 Jan;45(1):48-54. 